\title{
Произведения Елены Шварц в контексте направления женской прозы
}

\section{Elena Shvarts' Creative Work in the Context of Women's Fiction}

Кристина Владиславовна Воронцова

(Седльце, Польша)

\section{Абстракт:}

В центре внимания автора статьи - прозаические произведения Елены Шварц (1948-2010), ключевой фигуры ленинградского андеграунда 70-х годов XX века, известной в России и за ее границами в первую очередь благодаря своей визионерской необарочной поэзии. В работе предпринята первая в литературоведении комплексная попытка систематизировать и классифицировать прозу поэтессы по темам и жанровым особенностям, а также поместить ее в контекст женской прозы на русском языке.

\section{Ключевые слова:}

Елена Шварц; постмодернизм; женская проза; андеграунд; БДТ

\section{Abstract:}

The author of the article focuses on the prose works of Elena Shvarts (1948-2010), the key figure of the XXth century Leningrad underground of the 70s, who was known in Russia and beyond its borders primarily due to her visionary neo-baroque poetry. In this work, the first in the literary criticism complex attempt to systematize and to classify the prose of the poetess according to themes and genre features was made. Moreover, it was also placed in the context of the current of Women's fiction in Russian language.

\section{Key words:}

Elena Shvarts; postmodern; Women's fiction; underground; BDT 
Творчество Елены Шварц (1948-2010) как одной из ключевых фигур ленинградской второй культуры и эпохи самиздата 70-х годов XX века неизменно привлекало и продолжает привлекать внимание критиков и литературоведов. Нельзя, однако, отрицать, что мировую известность ей принесли в первую очередь поэтические произведения, оригинальные как с точки зрения свободной формы стихосложения, так и с точки зрения их визионерского содержания и необарочной эстетики. В стихах Шварц встречаются эпохи и цивилизации, культуры Востока и Запада, а взгляд поэтессы в поисках Бога охватывает все мироздание от микрокосма до «горних сфер».

Соответственно, и научное «шварцеведение» в России и за рубежом занимается в основном описанием и классификацией стихотворений, применяя для этого различные методологические подходы и концепции ${ }^{1}$. При этом нельзя отрицать, что практически половину творческого наследия автора составляют прозаические произведения, относящиеся к весьма разнообразным жанрам. В академической среде в настоящее время существует некоторая тенденция игнорировать эту сторону жизни Елены Шварц, хотя ее рассказы, повести, дневники, критические эссе и поэтические манифесты, без всякого сомнения, заслуживают особого внимания и интереса филологов. В данный момент назрела острая необходимость ввести в научный оборот эти новые материалы для будущего продуктивного филологического исследования и литературоведческого анализа ${ }^{2}$

Цель данной статьи - попытаться классифицировать прозаическое наследие автора в его целостности и однородности в соответствие с жанровыми особенностями и проблематикой, а также определить его специфическую позицию в парадигме русскоязычной женской прозы, дать теоретическую базу

1 Cм.: SABBATINI, M.: Nella giovinezza di Elena Švarc. Il testo e l'autore tra teatralità ed ecletti-smo poetico. Europa Orientalis, 2004, nr 1, s. 165-176; SABBATINI, M.: Elena Švarc "fiera-fiore”. In: "Quel Che Si Metteva In Rima”: Cultura E Poesia Underground a Leningrado. Salermo: Iniversita di Salermo, 2008, s. 266-278; ZITZEWITZ, J.: Elena Shvarts: Incarnation Inverted. In: ZITZEWITZ, J.: Poetry and the Leningrad Religious-Philosophical Seminar 1974-1980. Cambridge: Modern Humanities Research Association and Maney Publishing, 2015, s. 111-135; VORONCOVA, K. V.: «Prostranstvo-Vremja - Androgin...»: Modeli prostranstva v poèzii feleny Švarc. Kraków: Wydawnictwo Uniwersytetu Jagiellońskiego, 2016 и др.

2 Стоит, однако, заметить, что первые подготовительные шаги в изучении прозы Шварц уже сделаны: в Alma mater studiorum Università di Bologna в 2017/2018 учебном году лекция на эту тему входила в курс «Современная русская литература», по результатам которого студент-магистрант Риккардо Д’Алессандро представил индивидуальный проект о ранней прозе Елены Шварц Sono Venuto a Potare Il Fuoco Sulla Terra; e Come Vorrei Che Fosse Gia Acceso! La Prosa Giovanile di Elena Švarc. Кроме того, на конференции в Кракове Czas w kulturze rosyjskiej 21 сентября 2018 года был прочитан доклад об одной из поздних повестей автора: VORONCOVA, K. V.: Vremja kak postmodernistskaja igra v povesti feleny Švarc «Koncert dlja recenzij». $\langle$ В печати $\rangle$. 
для дальнейших исследований, которая может быть использована в том числе в эдиционной практике при подготовке художественных текстов к научному изданию.

Несмотря на то, что Шварц писала с подросткового возраста, первые официальные сборники прозы увидели свет довольно поздно: Определение в дурную погоду - в 1997 году, Видимая сторона жизни - в 2003. Во времена СССР из-за цензуры официальные толстые журналы и издательства были для поэтессы недоступны. Ее творчество распространялось в андеграундном самиздате, «тамиздате» (в США, Израиле, Франции) и на квартирных чтениях, после 1991 года стихи наконец стали печатать и в России, однако проза по-прежнему оставалась на периферии читательского внимания. После выхода в 2013 году V тома Сочинений Елены Швари с дневниками и текстом о Марине Цветаевой данная тема начинает вновь привлекать внимание критиков.

Именно в их работах сделаны первые попытки определить и описать неоднозначную жанровую природу прозы Шварц, ее синтетический феномен, и выявить традиции, в рамках которых автор конструирует художественные миры. Поэтесса изобрела термин для обозначения высшей барочной (конечно, и необарочной тоже) формы - «визьон-приключение», о котором в одном из интервью говорила как о любимом жанре, «который не знаешь, чем кончится» и в котором видение «творит само себя, приключается» ${ }^{3}$. Очевидно, что данное определение можно перенести и на прозу из-за глубинной связи с её собственной метафизической поэзией и непредсказуемости сюжета. Александр Уланов также рассматривает прозу Шварц как продукт побочный стихам, «автокомментарий и демонстрацию того сора, из которого...» ${ }^{4}$, а Петр Казарновский, говоря об автобиографических произведениях поэтессы, акцентирует внимание на том, что это дневник именно поэта, возникающий «на стыке внутреннего и внешнего ${ }^{5}$. Наталья Иванова в рецензии на Видимую сторону жизни отвергает предложенные издателем определения вроде эссе, мемуары и малая проза и дает собственное: «Параллельная жизнь поэта» ${ }^{6},-$ в другой работе критик ставит Елену Шварц в один ряд с обожаемой ею Мариной Цветаевой как автора, творящего в русле «non-fiction в прозе поэтов» ${ }^{7}$.

3 POLUCHINA, V.: Brodskij glazami sovremennikov. Sankt-Peterburg: Zvezda, 1997, s. 207.

4 ULANOV, A.: Zametki Geriona. Znamja, 1998, nr 4, s. 220-221.

5 KAZARNOVSKIJ, P.: «Sineva ranimaja...». NLO, 2014, $\mathrm{nr}$ 6. <http://magazines.russ.ru/nlo/2014/130/ 35k.html\#_ftn9>. [online]. [cit. 12.4. 2019].

6 IVANOVA, N.: Posledneje pokryvalo Salomei. Družba narodov, 2004, nr 9. <http://magazines.russ.ru/ druzhba/2004/9/iv19.html>. [online]. [cit. 12. 4. 2019].

7 IVANOVA, N.: Russkij krest. Literatura i čitatel' v načale novogo veka. Moskva: Vremja, 2011, s. 201. 
Валерий Шубинский, так же сравнивая лаконичность и афористичность стиля Шварц с Цветаевой, отмечает, что ее проза - «конспект настоящих литературных мемуаров, но конспект удивительно емкий и самодостаточный». Это, без сомнения, «проза поэта», но в этом и главная ее особенность, объясняющая синтетическую природу: «не проза в обычном смысле, не критика, даже не совсем эссеистика. Это особого рода тексты, рождающиеся по поводу стихов и в связи со стихами» ${ }^{8}$.

Олег Дарк, не отрицая поэтической сущности творчества автора, подходит к жанровому определению прозы несколько с иной точки зрения, используя средневековый термин миракль, «рассказ о чуде», и называя «чудо преображения» основой сюжета, а в некоторых случаях и «античудо» ${ }^{9}$. Более того, критик противопоставляет духовную поэзию Шварц ее более «человеческой» прозе. Андрей Немзер в свою очередь относит «мистические притчи» автора к так называемой «другой прозе», которая в перестроечные времена «не укладывалась в позднесоветский канон» ${ }^{10}$. При этом интересно, что данная формулировка, в понимании критика, противопоставлена «не другой» женской прозе Людмилы Улицкой и иных писательниц.

Несмотря на «затемненную» природу творчества автора и разнообразие жанров и форм, определенная гетерогенность мотивов, образов и проблематики позволяет выделить некоторые устойчивые группы и сделать первую попытку классификации, которая, само собой, может стать предметом дальнейшей академической дискуссии и уточнений. Таким образом, в результате целостного анализа художественных текстов, вошедших в пятитомное собрание сочинений Елены Шварц, удалось получить следующие группы, обладающие сходными формальными чертами и мотивными комплексами:

1. Non-Fiction поэта.

2. Философские и критические эссе.

3. Магический реализм трэвелога.

4. «Петербургская гофманиада»: рассказы и повести.

5. Мемуарная проза.

Первая группа - Non-Fiction поэта. К данному разделу относится ранняя повесть 1961 года Девочка со ста сорока восемью родинками, сборники Истинные происшествия моей жизни и Видимая сторона жизни, короткие рассказы Играй,

8 ŠUBINSKIJ, V.: Čudesnyj slučaj i tainstvennyj son. NLO, 2004, nr 66, <http://www.litkarta.ru/dossier/ shubinskiy-o-vidimoi-storone-zhizni-shwartz/dossier_4681/view_print/>. [online]. [cit. 1. 4. 2019].

9 DARK, O.: Volna i plamen'. Znamja, 2004, $\mathrm{nr}$ 8. <http://magazines.russ.ru/znamia/2004/8/dark14. html>. [online]. [cit. 1. 4. 2019].

10 NEMZER, A.: «Ne drugaja» proza. Vmesto žurnal'nogo obzora. 2003. <http://www.ruthenia.ru/nemzer/ jurnaly10_12.html>. [online]. [cit. 1. 4. 2019]. 
Адель, не знай печали..., И-Цзин, Так жили поэты, Путеводитель по стихам и Детский сад.

Все эти тексты объединяет автобиографическая героиня - чаще всего ребенок или подросток Лена Шварц, описывающая свой идеальный мир детства и путь в поэзию. В центре этого утопического топоса - образ Семьи, во главе которой - Мама, Дина Морисовна Шварц, бывшая в течение 4 л лет легендарным завлитом ленинградского БДТ, самый близкий человек Елены Андреевны, чью смерть в 1998 году поэтесса переживала как главную трагедию, а жизнь после - как полную одиночества и чувства сиротства. Прозаические произведения, относящиеся к данной группе, проливают свет на суть этих отношений и создают яркий портрет Дины Шварц, многие годы бывшей правой рукой режиссера Георгия Товстаногова. Топос детства здесь плотно связывается с топосом Театра, в котором поэтесса проводила время с ранних лет, между понятием Семья и Театр практически нет границы.

Герои Видимой стороны жизни - реальные исторические личности, члены театральной и литературной богемы: Георгий Товстоногов, Иннокентий Смоктуновский, Александр Вампилов, Анна Ахматова, Сергей Довлатов, Иосиф Бродский, Евгений Рейн и др. Рассказы о встречах с ними интересны прежде всего неожиданным детским или подростковым, порой бунтарским, взглядом на авторитеты, на людей, ставших культурными мифами русской культуры. Для маленькой Лены Шварц великие актёры советского кино и театра - близкие знакомые со своими недостатками, обычные коллеги Дины Морисовны, изображаемые без пиетета и в естественной алкогольно-богемной обстановке театральных гастролей, прогонов перед премьерами и репетициями. Именно в это время автор приходит к выводу: «тогда гастроли стали моим идеалом жизни» $\left(\right.$ Гастроли $\left.{ }^{11}\right)$. Этот мотив в разных вариациях будет постоянно повторяться в её прозе. В отрицании авторитетов пятнадцатилетняя Шварц-подросток идёт ещё дальше, и для неё даже Ахматова - просто ничего не понимающая старуха (Разговор в «Будке» $\left.{ }^{12}\right)$.

Второй круг персонажей, более интимный, - непосредственно члены семьи автора, описанные с нежностью и иронией: мама, дядя, бабушка, неизвестный (поистине мифологический) отец и Берта, женщина, удочерившая Дину Морисовну и её сестёр после сталинских репрессий. Эти семейные истории из Видимой стороны жизни, в которых автор стремится найти потайное чудесное дно, станут питательной средой для творчества Шварц вообще и будут в дальнейшем проникать и в не автобиографические повести. Так,

11 ŠVARC, Je.: Sočinenija feleny Švarc. T. 3. Sankt-Peterburg: Puškinskij dom, 2008, s. 180.

12 Там же, с. 190-192. 
например, реальный эпизод из раннего детства будущей поэтессы, связанный с днём смерти Сталина, из истории Способ передвижения ${ }^{13}$ повторится позднее в повести Концерт для рецензии и будет, словно наблюдаться со стороны выдуманным главным героем Семёркиным ${ }^{14}$ : так, персонаж встречается лицом к лицу с собственным автором и её матерью. Встреча эта рассчитана на постмодернистскую игру, на то, что потенциальный читатель знаком с кругом текстов Елены Шварц и оценит самоцитирование и игровое начало.

Сценографичность и афористичность нарратива позволили режиссеру Борису Павловичу и актрисе Яне Савицкой в 2010 году на основе сборника Видимая сторона жизни, эссе и стихотворений поэтессы создать одноименный моноспектакль, в котором Елена Шварц вернулась на сцену БДТ уже в качестве действующего лица.

Истинные происшествия моей жизни, в свою очередь, интересны как документ эпохи «квартирных чтений» и самиздата 70-х годов. Герои рассказов этого сборника - друзья Шварц, творческая богема: неофициальные поэты, художники, философы, критики. Вновь появляются реальные личности советского андеграунда: Сергей Довлатов, Евгений Рейн, Виктор Кривулин и многие др. Автор кропотливо и во всех подробностях изображает весьма сложные взаимоотношения между посетителями квартирных чтений, а так же то, что, собственно, составляло основу их богемного стиля жизни: эмоциональные скандалы, драки, злоупотребление алкоголем, искреннюю творческую свободу этого периода, неподцензуренность мировосприятия. Хотя стиль этих историй отличается документальностью и даже публицистичностью повествования, ленинградский быт эпохи застоя в них мифопоэтизируется и карнавализируется.

Совершенно очевидно, что тексты, относящиеся к группе Non-Fiction поэта, главной своей целью ставят формирование биографического мифа самой Шварц. Это всё же не документальные мемуары, а рассказы о людях через призму авторского восприятия, вписанные в контекст её творческого мира и необарочной интертекстуальной эстетики. Здесь поэтесса изображает поворотные, хотя и весьма прозаические, на обывательский взгляд, моменты своей жизни (от первого стакана вина в возрасте 11 лет до пожара, практически уничтожившего квартиру Шварц, её микрокосм), которым она придавала определённое мистическое значение и которые пыталась разгадать. Как замечала она сама: «мифотворчество тоже один из наших инстинктов. Мы и свою жизнь, и чужую не можем иначе осмыслить, чем миф» ${ }^{15}$. Кроме того,

13 Там же, с. 172.

14 ŠVARC, Je.: Sočinenija feleny Švarc. T. 4. Sankt-Peterburg: Puškinskij dom, 2008, s. 102.

15 ŠVARC, Je.: Sočinenija feleny Švarc. T. 3. Sankt-Peterburg: Puškinskij dom, 2008, s. 231-232. 
автор стремится показать, что и каким образом сформировало её как поэта и творца. Сакральная роль искусства и русских поэтов как последнего оплота настоящей поэзии - сквозная тема всего прозаического наследия Шварц.

Она же является центральной для второй обширной группы текстов, составленной философскими и критическими эссе, в которых объединяющим мотивом является образ Творца, Человека Говорящего. Для религиозного сознания Шварц особый интерес представляют дихотомии Человек - Творец, Человек - Демиург, Человек, созданный по образу и подобию и создающий по образу и подобию. Так появляются статьи о Маяковском, Тютчеве, Цветаевой, Аронзоне, Фете и других великих поэтах, а также попытки самоинтерпретации и манифестации своей поэзии в постмодернистском ключе. Каждый великий поэт, по мнению автора, несёт в себе искру божественного и именно поэтому видит больше, дальше и глубже.

При этом здесь также далеко от гомогенности жанра и продолжаются интертекстуальные игры с читателем. Так, например, Статья об Арнозоне в одном действии - это в самом деле мини-пьеса, действующими лицами которой становятся Смерть, Порфирий Петрович (иронично, что исполнителем этой роли значится Раскольников), Нерождённый ребёнок и автор под одной из своих узнаваемых масок ${ }^{16}$.

С помощью подобных постмодернистских экспериментов Шварц пытается разгадать истинный смысл искусства и ищет знаки запредельного в обыденности: метафизика повседневности, таким образом, становится ещё одним «фирменным знаком» прозы поэтессы.

В эту группу можно включить Маленькие эссе и Поэтику живого, а также крошечные, часто в одно предложение, эссе из сборника Определение в дурную погоду. Ключевой характеристикой этих текстов, несомненно, является краткая афористичность стиля, заимствованная во многом у Марины Цветаевой (например, знаменитое «Квадрат - это круг с крылышками» ${ }^{17}$ ), и сосредоточенность на собственном внутреннем мире, его психологических особенностях: «Можно подумать, что я склонна к самолюбованию. Скорее я пристально вглядываюсь в себя с пристальным вниманием экспериментатора, с каким он может следить за животным, опыты над которым наконец-то начали подтверждать теорию» ${ }^{18}$. Шварц интересует природа чистой истинной поэзии и Поэт как проводник божественного в физическом мире, именно поэтому она исследует себя как самый благодатный и доступный материал для подобной «научной работы».

16 ŠVARC, Je.: Sočinenija feleny Švarc. T. 4. Sankt-Peterburg: Puškinskij dom, 2008, s. 246.

17 ŠVARC, Je.: Sočinenija feleny Švarc. T. 3. Sankt-Peterburg: Puškinskij dom, 2008, s. 228.

18 Там же, с. 233. 
Это же скрупулёзное исследование продолжается в группе текстов, которую можно условно назвать Магический реализм трэвелога: в сборнике рассказов Литературные гастроли, а также в отдельных рассказах и очерках Поэтические спектакли, Первые Литературные гастроли, Путешествия, Итальянские мгновения. Они все объединены темой путешествия и принципом гастрольного идеала жизни, сформулированным ещё 11-летней Леной Шварц: вечное бродяжничество вслед за творчеством в поисках истинной поэзии, подлинно выход за пределы привычного, ведь «заграничная жизнь - подлинно за границей своих привычек» ${ }^{19}$.

Главная героиня этих произведений либо автобиографическая, либо носит привычную маску Тины Бриллиант (она же появляется, например, в статье о Леониде Аронзоне, упоминаемой выше), о которой автор предупреждает, продолжая постмодернисткую игру с читателем: «Она поэт. Она моих лет, она похожа на меня, как две капли воды. Но она не я!» ${ }^{20}$. Обширна география сюжета, при этом география передвижений Тины и реальной Елены Шварц совпадают, таким образом и создаётся иллюзия документальности, правдоподобности описываемых событий. Для этого же, как и в первой группе текстов, упоминаются и действуют реальные личности творческой богемы. В основном это поэты: Дмитрий Пригов, Евгений Евтушенко, Вероника Долина, Геннадий Айги и др. Читатель доверяет автору и нарративу, его внимание притупляется, он считает, что Литературные гастроли - это своеобразное продолжение гастролей детства, идеального «театра», однако именно на этом строит автор эффект неожиданности и обманутых ожиданий, когда ближе к концу, на фоне правдоподобных личностей, топонимов и событий возникают приёмы магического реализма, так называемая «внезапная фантастика», когда в абсолютно реалистическое повествование с заслуживающими доверия героями из реальной жизни начинают вплетаться фантасмагорические элементы: двухголовые азиаты, «пупы мира» (один из них, конечно, Петербург), всемирные потопы. Начиная с описания собственных поездок по различным поэтическим фестивалям и путевых впечатлений в стиле трэвелога, Шварц постепенно приходит к абсурдному финалу и концу света, символизирующему конец истинной поэзии, на место которой приходят верлибры, лишённые музыки высших сфер.

Четвёртая группа текстов - это рассказы и повести, написанные в традиции так называемой Петербургской гофманиады и в духе собственных стихотворений и поэм автора Общими с поэзией Шварц является так же

19 ŠVARC, Je.: Sočinenija feleny Švarc. T. 4. Sankt-Peterburg: Puškinskij dom, 2008, s. 179.

20 Там же, с. 178. 
и сосредоточенность на вечных темах и антиномиях, таких как: Плоть и Дух, Бог и Человек, смерть и жизнь, старение. Как истинная коренная петербурженка Шварц испытывала на себе влияние петербургского текста русской литературы с его фантастикой, гротеском, фантасмагориями, абсурдом, нарочитой кукольностью персонажей, урбанистичностью, перенасыщенностью литературными цитатами и амбивалентностью. Все эти черты можно найти и в её версии Петербургской гофманиады. К этой группе текстов относятся ранние рассказы 6о-х и 70-х годов: Письмо из желтого дома (1966 г.), Сны (1967 г.), Болезнь (1967 г.), Огонь небесный (1967 г.), Бабушка (1967 г.), Соседка (1968 г.), Уйди, не снись, крысиныцй хвостик (1970 г.), Рассказ о любви, Блудныцй сын, - а также повести разных лет: Комедиальныцй правитель (1971 г.), Взрывь и гомункульь (1979 г.), Трогальщик (2003 г.) и Концерт для рецензий (2007 г.). В этих произведениях родной город автора изображается в различные периоды своей трагической истории, выступая и как Петроград, и как Санкт-Петербург, и как Ленинград.

Персонажи максимально отстранены от автора, хотя порой Щварц и «делится» с ними эпизодами своей биографии, зашифровывает те или иные события собственной жизни в списке чтения или встречах главных героев.

К последней группе прозаических текстов относится непосредственно мемуарная проза, которая частично составила 5 том собрания сочинений, всё, что удалось спасти после пожара 2004 года, и всё, что было написано после: а именно Дневники 1957-1966 и Дневники 20о1-2011, в которых Шварц кратко, откровенно и с юмором описывает свою жизнь, встречи с друзьями и коллегами. Главным героем её последних дневников является пёс Хоку породы японский хин, которого поэтесса приобрела на выставке собак в 2006 году и который оставался с ней до конца её жизни.

Как мы можем видеть, проза Елены Шварц отличается исключительным жанровым разнообразием. Можно ли вписать обширное и разнообразное прозаическое наследие Елены Шварц в узкие рамки какого-либо направления современной русской литературы? Целесообразно ли анализировать его, например, в контексте русской женской прозы наравне с Татьяной Толстой, Людмилой Петрушевской, Людмилой Улицкой и другими? С определенной долей условности это сделать удается. Конечно, сама поэтесса никогда не ассоциировала себя с Women's writing ${ }^{21}$, однако совершенно очевидно, что многие паттерны в творчестве женщин-прозаиков совпадают.

21 Более того, гендерный вопрос как таковой в стихотворных текстах Шварц долгие годы практически отсутствует, и возникает в последние годы жизни в связи с рефлексией, вызванной старением и принятием возрастных изменений женского тела. 
Вслед за авторами, теоретически разрабатывающими аспекты женской прозы $^{22}$ попробуем в текстах Елены Шварц выделить черты, отвечающие всему направлению в целом.

Во-первых, гендер и автора, и других протагонистов в большинстве случае совпадают, поэтому перед читателем раскрывается взгляд на мир, с точки зрения женщины, и с учетом гендерных особенностей женской психологии.

Во-вторых, общим местом женской прозы является изображение мира семьи, детства как «потерянного рая», а также сам по себе «детский взгляд» на прекрасный и страшный мир вокруг. Те же самые темы являются центральными в творчестве Шварц, что хорошо видно на приведённых выше примерах. Среди неавтобиографических персонажей повестей и рассказов поэтессы, как и в произведениях Татьяны Толстой и Людмилы Улицкой, частотен новый вариант типа «маленького человека» 20-21 века: заеденный советским бытом интеллигент, философ, ведущий диспуты о смысле бытия с котом, выпавший из действительности позднего сталинизма или эпохи застоя мечтатель, обязательно Человек Говорящий и немного демиург собственного мира.

B-третьих, и для прозы рассматриваемого автора, и для всего направления русского Women's writing характерна контаминация художественного и публицистического в стиле, подчеркнутый автобиографизм, «жесткий реализм» и парадоксальность, абсурд, экспрессивность. Примеры подобного можно найти и в эссе Татьяны Толстой, и в трэвелогах Марии Арбатовой.

В-четвертых, для текстов Елены Шварц, как и для других авторов женской прозы, особое значение имеет интертекстуальность как таковая, мифопоэтика и библейские аллюзии. Её произведения - интеллектуальная игра с читателем, рассчитанная на узнавание культурного кода, возникшая на стыке постмодернистской эстетики и реализма.

B-пятых, часто в основе сюжета лежит поток сознания, а языковая личность автора и её героев в высшей мере индивидуализирована.

B-шестых, на философском уровне Елену Шварц с другими авторами женской прозы объединяет, само собой, путь от быта к бытию, умение увидеть метафизику, чудесное в обыденном.

Таким образом, очевидно, что автор, даже не идентифицируя себя с направлением русской женской прозы, во многом предвосхитила художественные открытия женщин-писательниц, а затем создавала произведения, вписывающиеся в устанавливающийся канон Women’s writing.

22 См. работы М. А. Черняк, И. Г. Замбулидзе и др. 
Представленная в статье типология художественных жанров прозаических текстов Елены Шварц, без сомнения, требует дальнейшего дополнения и методологических уточнений, однако может считать первым шагом в будущем осмысления творчества автора во всей его целостности. Отдельного внимания заслуживает образ главной героини, представленный многочисленными масками, и вопрос о том, насколько она отражает авторское самосознание, а также эволюция типа «маленького человека» русской литературы в контексте направления женской прозы.

\section{Литература:}

ČERNJAK, M.A.: Ženskij počerk $v$ sovremennoj proze: T. Tolstaja, L. Ulickaja, L. Petruševskaja, V. Tokareva, Je. Dolgopjat. In: ČERNJAK, M. A.: Sovremennaja russkaja literatura. Moskva: Forum, 2010, s. 161-187. ISBN 978-5-91134-101-5.

DARK, O.: Volna i plamen'. Znamja, 2004, nr 8. <http://magazines.russ.ru/znamia/2004/ 8/dark14.html>. [online]. [cit. 1. 4. 2019].

IVANOVA, N.: Posledneje pokryvalo Salomei. Družba narodov, 2004, nr 9. <http:// magazines.russ.ru/druzhba/2004/9/iv19.html>. [online]. [cit. 12. 4. 2019].

IVANOVA, N.: Russkij krest. Literatura i čitatel' v načale novogo veka. Moskva: Vremja, 2011. ISBN: 978-5-9691-0959-9.

KAZARNOVSKIJ, P.: «Sineva ranimaja...». NLO, 2014, nr 6. <http://magazines.russ.ru/ nlo/2014/130/35k.html\#_ftn9>. [online]. [cit. 12.4. 2019].

NEMZER, A.: «Ne drugaja» proza. Vmesto žurnal'nogo obzora. 2003. <http://www. ruthenia.ru/nemzer/jurnaly10_12.html>. [online]. [cit. 1. 4. 2019].

POLUCHINA, V.: Brodskij glazami sovremennikov. Sankt-Peterburg: Zvezda, 1997. ISBN 978-5-87184-522-6.

SABBATINI, M.: Nella giovinezza di Elena Švarc. Il testo e l'autore tra teatralità ed ecletti-smo poetico. Europa Orientalis, 2004, nr 1, s. 165-176. ISSN 0392-4580.

SABBATINI, M.: Elena Švarc “fiera-fiore”. In: "Quel Che Si Metteva In Rima”: Cultura E Poesia Underground a Leningrado. Salermo: Iniversita di Salermo, 2008, s. 266-278. ISBN 978-88-62350-18-1.

ŠUBINSKIJ, V.: Čudesnyj slučaj i tainstvennyj son. NLO, 2004, nr 66, <http://www. litkarta.ru/dossier/shubinskiy-o-vidimoi-storone-zhizni-shwartz/dossier_4681/view _print/>. [online]. [cit. 1. 4. 2019].

ŠVARC, Je.: Sočinenija feleny Švarc. T. 3. Sankt-Peterburg: Puškinskij dom, 2008.

ŠVARC, Je.: Sočinenija feleny Švarc. T. 4. Sankt-Peterburg: Puškinskij dom, 2008. 
ULANOV, A.: Zametki Geriona. Znamja, 1998, nr 4, s. 220-221.

VORONCOVA, K. V.: «Prostranstvo-Vremja - Androgin...»: Modeli prostranstva v poèzii feleny Švarc. Kraków: Wydawnictwo Uniwersytetu Jagiellońskiego, 2016. ISBN 978-83-233-4094-2.

VORONCOVA, K. V.: Vremja kak postmodernistskaja igra v povesti feleny Švarc «Koncert dlja recenzij». 〈В печати $\rangle$.

ZITZEWITZ, J.: Elena Shvarts: Incarnation Inverted. In: ZITZEWITZ, J.: Poetry and the Leningrad Religious-Philosophical Seminar 1974-1980. Cambridge: Modern Humanities Research Association and Maney Publishing, 2015, s. 111-135. ISBN 978-1-909662-92-6.

ZUMBULIDZE, I. G.: «Ženskaja proza» v kontekste sovremennoj literatury. In: Sovremennaja filologija. Ufa: Leto, 2011, s. 21-23. ISBN 5-87308-035-6.

\section{About the author}

\section{Kristina Vorontsova}

Siedlce University of Natural Sciences and Humanities, Faculty of Humanities, Institute of Linguistics and Literary Studies, Siedlce, Poland kristina.vorontsova@uph.edu.pl 